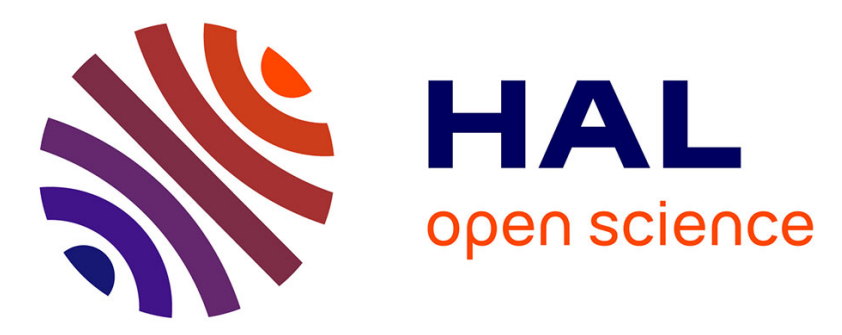

\title{
Selective impairment of sensorimotor representations following short-term upper-limb immobilization
}

\author{
Aurore Meugnot, Nounagnon Frutueux Agbangla, Lucette Toussaint
}

\section{To cite this version:}

Aurore Meugnot, Nounagnon Frutueux Agbangla, Lucette Toussaint. Selective impairment of sensorimotor representations following short-term upper-limb immobilization. Quarterly Journal of Experimental Psychology, 2016, 69 (9), pp.1842 - 1850. 10.1080/17470218.2015.1125376 . hal-01722561

\section{HAL Id: hal-01722561 \\ https://hal.science/hal-01722561}

Submitted on 4 Mar 2018

HAL is a multi-disciplinary open access archive for the deposit and dissemination of scientific research documents, whether they are published or not. The documents may come from teaching and research institutions in France or abroad, or from public or private research centers.
L'archive ouverte pluridisciplinaire HAL, est destinée au dépôt et à la diffusion de documents scientifiques de niveau recherche, publiés ou non, émanant des établissements d'enseignement et de recherche français ou étrangers, des laboratoires publics ou privés. 
Meugnot, A., Agbangla, N.F., \& Toussaint, L. (2016). Selective impairment of sensorimotor representations following short-term upper-limb immobilisation. Quarterly Journal of Experimental Psychology, 69(9), 1842-1850. doi:10.1080/17470218.2015.1125376

\section{Selective impairment of sensorimotor representations following short-term upper-limb immobilisation}

Aurore MEUGNOT, Nounagnon Frutueux AGBANGLA and Lucette TOUSSAINT*

Université de Poitiers

Centre de Recherches sur la Cognition et l'Apprentissage

CeRCA, CNRS / UMR 7295

5 rue Théodore Lefebvre

F -86000 Poitiers

Running head: Specific body-part representation

* Corresponding author: Lucette TOUSSAINT

CeRCA, CNRS / UMR 7295, 5 rue Théodore Lefebvre, 86000 Poitiers, France

Email: lucette.toussaint@univ-poitiers.fr

Web: http://cerca.labo.univ-poitiers.fr

Phone: +33 (0)549454698

Fax: +33 (0)5 49454616

Keywords: limb immobilisation; hand/foot laterality task; sensorimotor representation;

implicit motor imagery 


\begin{abstract}
In the present experiment, we examined whether short-term upper-limb immobilisation would selectively affect the representation of the immobilised limb (using a hand laterality task) or if the effect of immobilisation would extend to another body part (using a foot laterality task). A rigid splint placed on the participants' left hand was used for immobilisation. A control group did not undergo the immobilisation procedure. We compared the participants' performances on the hand and foot laterality tasks before $\left(\mathrm{T}_{1}\right)$ and after $\left(\mathrm{T}_{2}\right)$ a 48-hour delay, corresponding to the immobilisation period. For controls, response time analysis indicated a benefit of task repetition for the recognition of both hand and foot images. For the immobilised group, a slowdown of performance appeared in $\mathrm{T}_{2}$ for hand images, but not for foot images. The reduced benefit of task repetition following left-hand immobilisation appeared for both the immobilised and non-immobilised hand images. These findings revealed that the general cognitive representation of upper-limb movements is affected by the decrease in input/output signal processing due to the left-hand immobilisation, while the cognitive representation of lower-limb movements is not.
\end{abstract}




\section{Introduction}

Introduced in neuroscience for the first time in 1890 by William James, the concept of plasticity refers to the inherent property of the nervous system to reorganise itself according to environmental demands. Plasticity is an interesting concept in cognitive sciences because it leads to a functional reorganisation of the central nervous system that might be observable at the behavioral level. The majority of studies that have focused on the plasticity of the sensorimotor system use two main approaches (see Pascual-Leone, Amedi, Fregni, \& Merabet, 2005, for a review) based either on a rich and stimulating environment (e.g., in motor learning) or on an impoverished environment (e.g., with sensorimotor deprivation). In the latter case, short-term limb immobilisation (10-12 hours to 4 days) appears as a novel paradigm to explore the continuous and rapid updates to the sensorimotor representations caused by peripheral factors. Neuronal evidence has indicated that limb non-use induces a decrease in motor cortex excitability contralateral to the immobilised limb (Avanzino, Bassolino, Pozzo, \& Bove, 2011; Avanzino, Pelosin, Abbruzzese, Bassolino, Pozzo, \& Bove, 2013; Facchini, Romani, Tinazzi, \& Aglioti, 2002; Huber, Ghilardi, Massimini, Ferrarelli, Riedner, Peterson, \& Tononi, 2006). In parallel, behavioral studies have shown that sensorimotor restriction alters the central functioning of the sensorimotor system and may disrupt motor performance (Bassolino, Bove, Jacono, Fadiga, \& Pozzo, 2012; Huber et al., 2006; Moisello, Bove, Huber, Abbruzzese, Battaglia, Tononi, \& Ghilardi, 2008) or action simulation (Meugnot, Almecija, \& Toussaint, 2014; Meugnot, Agbangla, Almecija, \& Toussaint, 2015; Meugnot \& Toussaint, 2015; Toussaint \& Meugnot, 2013) of the restricted and unrestricted limbs.

Studies on the central and functional effects of short-term limb immobilisation have based their reasoning on the simulation theory, which states that covert and overt actions share the same sensorimotor representations and rely on the same mechanisms (Jeannerod, 
2001). Therefore, motor imagery tasks were used to examine the immobilisation-induced effects (i.e., the decrease in input/output signal processing) on sensorimotor representations. The effect of sensorimotor deprivation was often evaluated using mental rotation tasks that are well known to implicitly trigger mental imagery strategies. In these tasks, participants are instructed to identify as accurately and as quickly as possible an image presented on the computer screen in different orientations (Parsons, 1994; Shepard \& Metzler, 1971). When images represent objects such as geometrical figures or Arabic numbers, participants usually use visual imagery to solve the task, a strategy independent of the sensorimotor processes (de Lange, Hagoort, \&Toni, 2005; Kosslyn, DiGirolamo, Thompson, \& Alpert, 1998). By contrast, when body-part images are used, participants usually refer to motor imagery to identify hand laterality. Therefore, the hand laterality task is ideal to investigate whether the internal upper-limb representations are affected by peripheral factors such as the input/output restriction of signal processing due to hand immobilisation.

In recent experiments investigating the effects of immobilisation on sensorimotor representations, healthy young adults usually wore a splint on their upper limb (the left or the right hand) for 24 hours (Meugnot et al., 2014, 2015) or 48 hours (Meugnot \& Toussaint, 2015; Toussaint \& Meugnot, 2013). Overall, the results showed that the immobilised participants took more time to identify images representing the immobilised hand, whereas their performance on the visual imagery task (i.e., using object images) was not affected following sensorimotor restriction. Moreover, the effect of immobilisation varied according to the duration of splint-wearing. A selective effect appeared following 24 hours of upper-limb immobilisation, as revealed by slower responses to images portraying the immobilised hand (either the left or the right hand) compared to the non-immobilised hand (Meugnot et al., 2014, 2015). By contrast, after 48 hours of sensorimotor deprivation, an independent-effector effect appeared, resulting in a slow-down of the sensorimotor processes for images 
corresponding to both the immobilised and non-immobilised hand (Meugnot \& Toussaint, 2015; Toussaint \& Meugnot, 2013). These results suggested that inter-limb (or inter-manual) transfer may occur in the case of sensorimotor deprivation, and may suggest that the movement simulation processes used in a body-part mental rotation task would elicit an abstract representation of the body influenced by peripheral changes. Note that currently, the issue of embodiment remains controversial in the motor simulation domain and the exact content of representations solicited by motor imagery is still unclear. Some studies highlighted the independent-effector effects (Curtze, Otten, \& Postema, 2010; Johnson, Sprehn, \& Saykin, 2002; Toussaint \& Meugnot, 2013), while others revealed the embodied nature of motor imagery processes (Ionta, Fourkas, Fiorio \& Aglioti, 2007; Meugnot et al., 2014; Nico, Daprati, Rigal, Parsons \& Sirigu, 2004).

Our study aimed to go further in understanding the immobilisation-induced effects on the sensorimotor representations. This has a great interest at both the theoretical and practical levels, to further identify the effects induced by short-term sensorimotor deprivation on the functioning of the sensorimotor system, and to organize rehabilitation programs to compensate for the slowdown of sensorimotor processes due to the decrease in input/output signal processing in immobilised patients. In the present experiment, we specifically examined whether short-term upper-limb (i.e., the left hand) immobilisation would strictly affect the sensorimotor representations of the immobilised limb (i.e., the hand) or if this effect would extend to other body parts such as lower extremities (i.e., the foot). In the first case, the results would suggest that the slowdown of the sensorimotor processes to the left hand identification spreads to the right hand, via interhemispheric transfer. In the second case, the slowdown of the sensorimotor processes for the identification of both hand and foot images would suggest that the upper-limb immobilisation-induced effects spread to the whole-body sensorimotor representation (i.e., from the upper-limb to the lower-limb system). For this 
purpose, we compared the performance of left-hand immobilised and control participants in two body-part mental rotation tasks using either foot or hand images. Participants performed the two tasks before $\left(T_{1}\right)$ and after $\left(T_{2}\right)$ a 48-hour delay, corresponding to the left-hand nonuse period in the immobilised group. If sensorimotor deprivation selectively affects the restricted body part, we expected an immobilisation-induced effect only for the hand laterality task. Indeed, in agreement with previous studies (Meugnot et al., 2014, 2015; Meugnot \& Toussaint, 2015; Toussaint \& Meugnot, 2013), a slowdown of the sensorimotor processes should be observed (in $\mathrm{T}_{2}$ ) for both the immobilised and non-immobilised hand recognition for participants who wore a splint for 48 hours (not for controls). Such a result would confirm that 48 hours of left-hand immobilisation affects the general cognitive representation of hand movements. By contrast, if the left-hand immobilisation-induced effects can be generalised to different effector-systems, recognition of body-part images should be slower for both hand and foot imagery tasks. Such a result would mean that the decrease in input/output signal processing not only causes an alteration in the representation of a specific body part but also may lead to a general slowdown of the whole sensorimotor system.

\section{Method}

\section{Participants}

Twenty-four right-handed university students $(M$ age $=19.8$ years; $S D=1.2)$ participated in the experiment. Their handedness was determined using the ten-item version of the Edinburgh inventory (Oldfield, 1971). Participants were divided in two groups. The control group ( $\mathrm{n}=12)$ was composed of 5 men and 7 women, aged between 18 to $21(M$ age $=19.5$ years, $\mathrm{SD}=1.2)$. The immobilised group $(n=12)$ was composed of 8 men and 4 women, aged between 18 to 22 $(M$ age $=20.2$ years, $\mathrm{SD}=1.3)$. Each participant was healthy, had normal or corrected-tonormal vision and no history of motor or neurological disorders. The local ethics committee 
approved the study protocol. The study has been performed in accordance with the ethical standards as laid down in the 1964 Declaration of Helsinki or comparable standards. All participants provided their written informed consent prior to their inclusion in this study. Before testing, the participants were naïve to the aim of the experiment.

\section{Materials and task}

All participants performed two body-part mental rotation tasks, one with hand-images (i.e., the hand laterality task) and the other with foot-images (the foot laterality task; see Figure 1). In these tasks, participants had to determine whether a hand or a foot image (created with Poser 6.0 software; size: $15.7 \mathrm{~cm}$ in height, 13.5 in width) was a left or a right hand/foot. Body-part images were presented in different orientations in the picture plane: $40^{\circ}, 80^{\circ}, 120^{\circ}$, and $160^{\circ}$ in two directions (clockwise and counterclockwise).

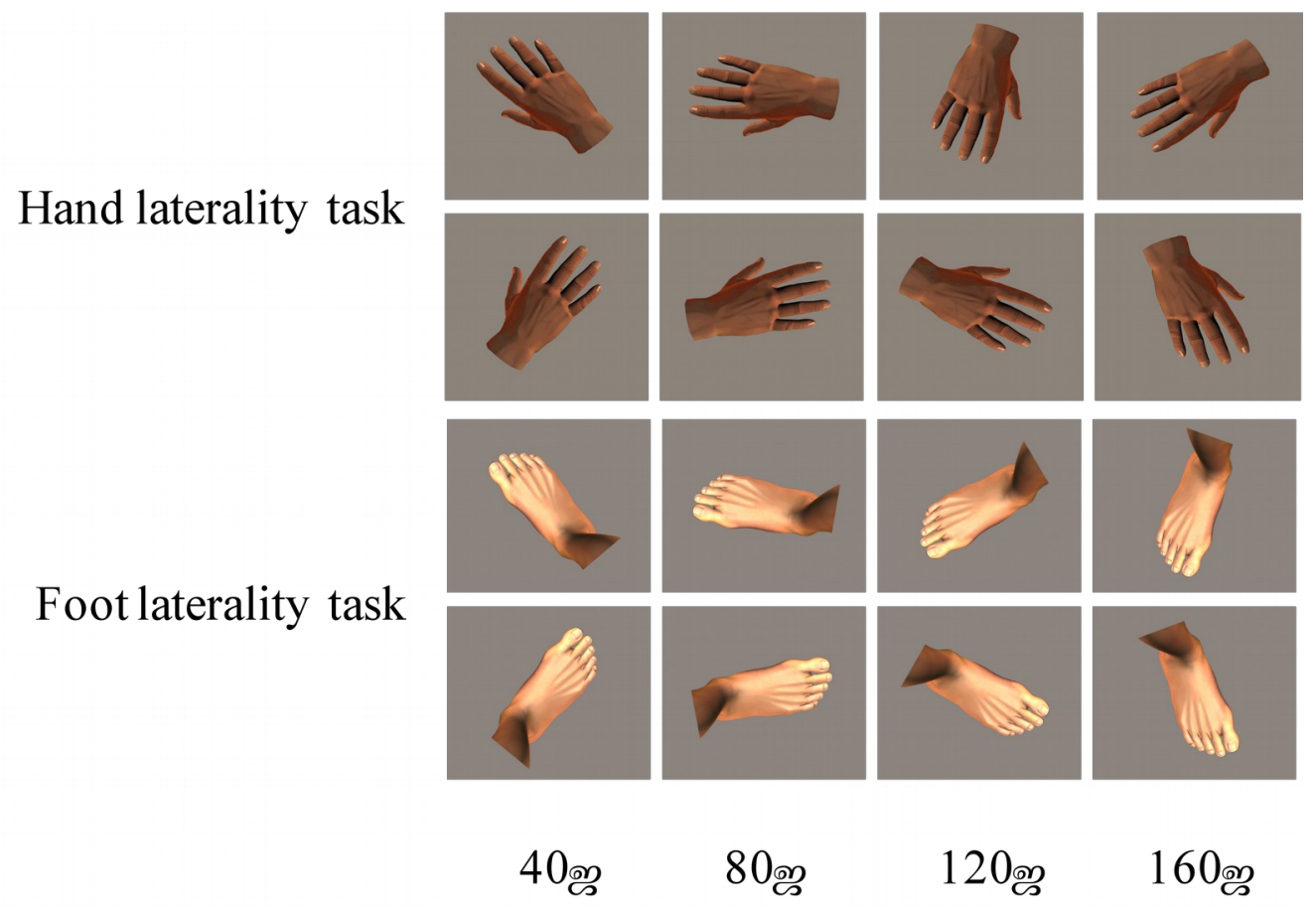

Figure 1. Example of body-part images used in the study. Only right hand and foot images are illustrated. 
For each task, participants were seated approximately $60 \mathrm{~cm}$ in front of the computer screen with their hands resting palm down on their laps. Participants were asked to identify body-part images displayed in the centre of the computer screen as accurately and as quickly as possible. Each trial began when a fixation cross was displayed in the centre of the screen for $500 \mathrm{~ms}$. Then, a body-part image was presented and remained visible until the participant gave a verbal response ("gauche"/"droite", two French words meaning "left"/"right", respectively). Verbal responses rather than key pressing responses were used to avoid interference with cognitive processes implied in the hand or foot laterality tasks (see Meugnot et al., 2014). The E-Prime 2.0 software package (Psychology Software Tools Inc., Pittsburgh, USA) was used to present body-part images and record the participants' response time via a microphone connected to the computer. For each trial, the response time corresponded to the time between the body image display and the first letter of the word pronounced by the participant (i.e., "gauche"/"droite"). The experimenter wrote the participants' answer on a sheet.

\section{Procedure}

The hand and foot laterality tasks were performed in two experimental sessions that were 48 hours apart $\left(\mathrm{T}_{1}\right.$ and $\left.\mathrm{T}_{2}\right)$. The order of presentation of the tasks was counterbalanced across participants (hand-foot tasks vs. foot-hand tasks). For all participants the laterality tasks were divided into two phases. During the first familiarisation phase, the participants were shown 16 randomly presented trials ( 2 hands or feet $\mathrm{x} 2$ directions $\mathrm{x} 4$ rotations). No speed-accuracy constraints were imposed during the familiarisation phase. During the second experimental phase, the participants were shown 5 blocks of 16 trials (i.e., 80 trials per participant) presented in a random order. The participants identified the laterality of hand or foot images as accurately and as quickly as possible. 
Immediately after $T_{1}$, we immobilised the left hand of the immobilised group. The other group served as the control (i.e., without immobilisation). We used a rigid splint (model DONJOY “Comfort Digit"; DJO, Surrey, UK) to immobilise the wrist and three fingers (index, middle and ring fingers) of the participants. Their immobilised arm was placed in a sling to ensure that the participants kept their hand at rest as much as possible during the 2 days of immobilisation. To quantitatively verify whether participants followed the instructions, we monitored the physical activity of both hands through actimeters (pounds/min) placed on each hand. The immobilised participants were instructed to never remove the splint or the actimeters and to keep the left-hand at rest during the immobilisation period. During the 48 hours delay, on average 314 pounds/min $(S D=105)$ were recorded for the immobilised hand and 946 pounds/min $(S D=201)$ for the non-immobilised hand (see Toussaint \& Meugnot, 2013, for a similar procedure). An ANOVA performed on the actimeters values showed that the level of activity was significantly higher for the right-hand than for the left-hand, $F(1,11)=95.84, M S E=25062, p=.0001, \eta^{2}=.90$. For the immobilisation groups, the post-test was performed immediately after the splint removal.

\section{Data Analysis}

Accuracy and response time were recorded for each trial. Only data from correct responses were used to analyse response time. Response times less than $400 \mathrm{~ms}$ were excluded from the analyses (less than $2 \%$ regardless of session and task; see Parsons, 1994, for a similar procedure). No significant Pearson correlation was found between accuracy scores and response times in each group, for each session, each body part and each body side, indicating no speed-accuracy trade-off $(p s>.15)$. ANOVAs were performed on both accuracy $(\%)$ and response times (ms) with group (control vs. immobilised) as a between-subjects factor, and body part (hand vs. foot), session ( $\mathrm{T}_{1}$ vs. $\left.\mathrm{T}_{2}\right)$, body side (left vs. right) and rotation $\left(40^{\circ}, 80^{\circ}\right.$, 
$120^{\circ}, 160^{\circ}$ ) as within-subjects factors. Post hoc comparisons were carried out by means of a Newman-Keuls Test. The alpha was set at .05 for all analyses.

\section{Results}

The ANOVA performed on accuracy (i.e., the percentage of correct responses) showed a significant effect of rotation, $F(3,66)=16.02, M S E=.0121, p=.0001, \eta_{p}^{2}=.42$, with only less accurate performance for the $160^{\circ}$ stimuli rotation $(M=90 \%, S D=10 \%)$ compared to the other stimuli $(M=96 \%, S D=7 \%, p s<.001)$. A trend toward significance was observed for session, $F(1,22)=3.49, M S E=.0282, p=.07, \eta_{p}^{2}=.14$, with less accurate performance in $\mathrm{T}_{1}$ $(M=94 \%, S D=9 \%)$ than in $\mathrm{T}_{2}(M=96 \%, S D=7 \%)$.

The ANOVA performed on response time yielded significant effects for body part, $F(1,22)=12.18, M S E=35950, p=.002, \eta_{p}^{2}=.36$, session, $F(1,22)=46.7, M S E=96920, p$ $=.000, \eta_{p}^{2}=.68$, body side, $F(1,22)=58.6, M S E=41754, p=.000, \eta_{p}^{2}=.72$ and rotation, $F(3,66)=38.01, M S E=72897, p=.000, \eta^{2}=.63$. The main effect of rotation resulted from faster responses for body-part images displayed at $40^{\circ}(M=875 \mathrm{~ms}, S D=185 \mathrm{~ms})$ and $80^{\circ}$ $(M=901 \mathrm{~ms}, S D=194 \mathrm{~ms})$ than at $120^{\circ}(M=966 \mathrm{~ms}, S D=216 \mathrm{~ms}, p s<.02)$, which in turn were faster than at the $160^{\circ}$ rotation $(M=1141 \mathrm{~ms}, S D=329 \mathrm{~ms}, p=.001)$. We also found two significant interactions: body part x session, $F(1,22)=4.62, M S E=22450, p=.04, \eta^{2} p$ $=.17$, and body part $\mathrm{x}$ session $\mathrm{x}$ group, $F(1,22)=6.44, M S E=22450, p=.018, \eta^{2}=.22$. The breakdown of the body part $\mathrm{x}$ session $\mathrm{x}$ group interaction (Figure 2) revealed that response times significantly decreased from $T_{1}$ to $T_{2}$ in both groups and for both hand and foot images $(p<.014)$. Importantly, although response times did not significantly vary between hand and foot images in the control group (in $\mathrm{T}_{1}$ and in $\mathrm{T}_{2}, p s>.09$ ), a different pattern of results appeared in the immobilized group. We can effectively see that following 2 days of left hand 
immobilization, responses were faster (in $\mathrm{T}_{2}$ ) when participants had to identify foot images $(M=914 \mathrm{~ms}, S D=166 \mathrm{~ms})$ than hand images $(M=1016 \mathrm{~ms}, S D=141 \mathrm{~ms} ; p=.0004)$, while no significant differences appeared before immobilization (in $\left.\mathrm{T}_{1}\right)(p=.98)$. Note that no significant differences appeared in the baseline performance (i.e., in $\mathrm{T}_{1}, p s>.65$ ) between groups, as well as in $\mathrm{T}_{2}$ for foot images $(p=.44)$.

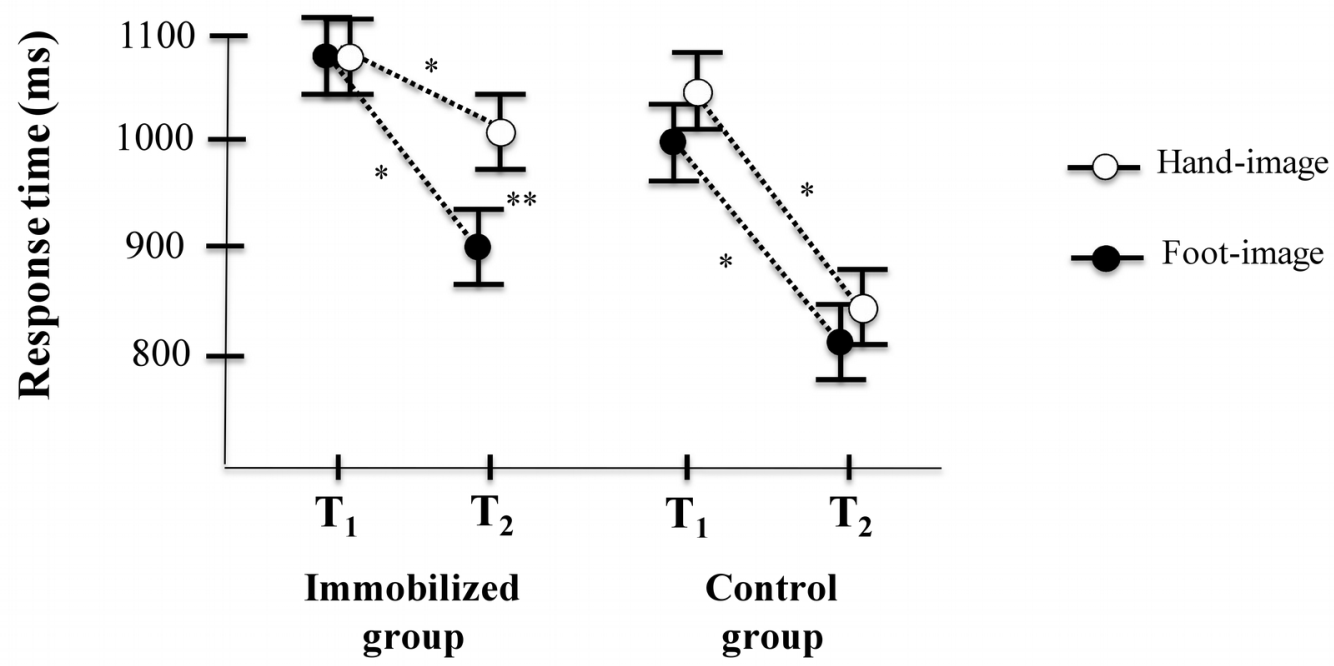

Figure 2. Response time (ms) as a function of body-part (hand versus foot), session $\left(\mathrm{T}_{1}\right.$ versus $\mathrm{T}_{2}$ ) and group (control versus immobilised groups). Error bars indicate the standard error of the mean.

\section{Index of Performance Improvement}

To quantify how the left hand immobilization leads to the improvement in response time in $\mathrm{T}_{2}$, we computed the Index of Performance Improvement $\left(\mathrm{IPI}=\left[\right.\right.$ response time in $\mathrm{T}_{1}$ response time in $T_{2}$ ] / response time in $T_{1}$, expressed in percentage) for each participant, and for each body part and body side. A positive value indicated that response times decrease from $T_{1}$ to $T_{2}$ (i.e., performance improvement), whereas a negative value indicated that response times increase (i.e., performance deterioration). IPI was analyzed by an ANOVA with group (control vs. immobilized) as a between-subjects factor, body part (hand vs. foot) 
and body side (left vs. right) as within-subjects factors. T-tests were used to examine whether the IPI significantly differed from zero.

The ANOVA revealed a significant main effect of body part, $F(1,22)=6.79, M S E=$. $009, p<.016, \eta_{p}^{2}=.24$, and a significant group $\mathrm{x}$ body part interaction, $F(1,22)=6.16, M S E$ $=.009, p<.021, \eta_{p}^{2}=.22$. The breakdown of the interaction (Figure 3) revealed that the IPI was lower for the hand images $(M=5 \%, S D=3.8 \%)$ than for the foot images $(M=15 \%, S D$ $=3.1 \%)$ in the immobilized group $(p=.002)$, whereas no significant difference appeared in the control group (hand images: $M=17 \%, S D=3.0 \%$; foot images: $M=17 \%, S D=2.6 \%, p=$ .93). Moreover, the IPI was significantly lower for the hand images in the immobilized group than in the control group ( $p=.014)$, without group differences for the foot images $(p=.81)$. T-test analyses showed that the IPI was significantly different from zero for foot images in the control group, $t(11)=9.02, p=.0001$ and in the immobilized group, $t(11)=4.88, p=.0006$, as well as for hand images in the control group, $t(11)=6.25, p=.0001]$, whereas it did not differ from zero in the immobilized group, $t(11)=1.38, p=.19$.

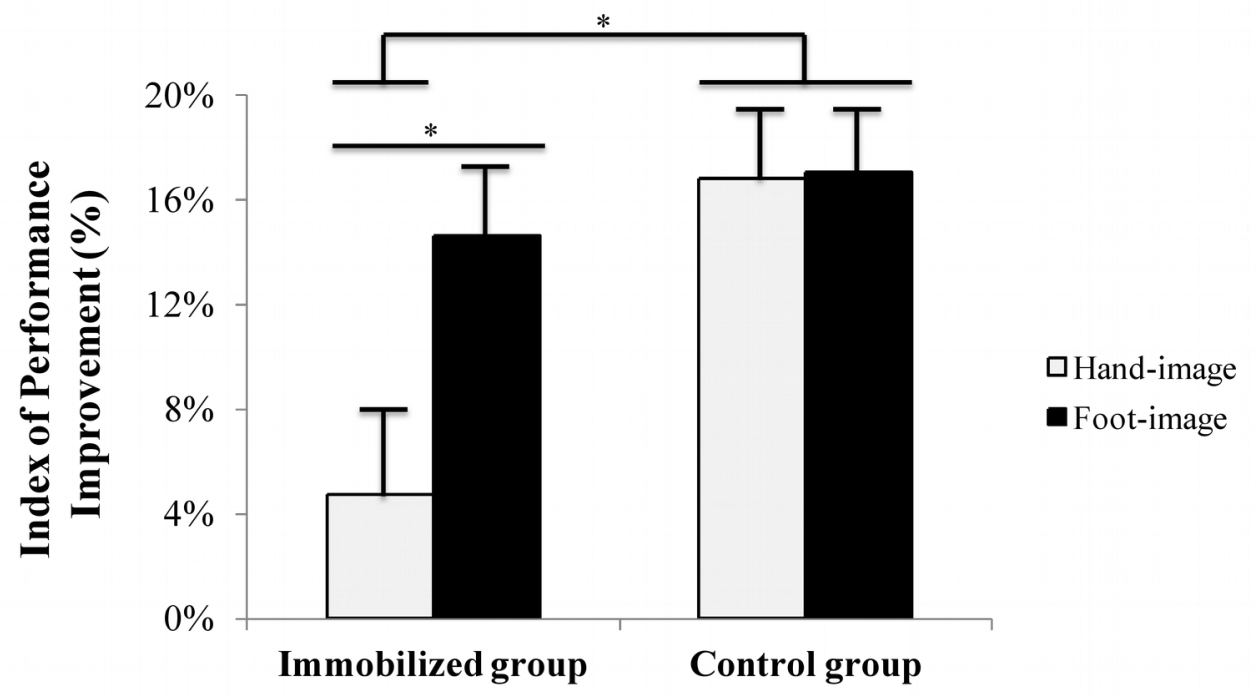

Figure 3. Index of Performance Improvement (\%) as a function of body-part (hand versus foot), session ( $T_{1}$ versus $T_{2}$ ) and group (control versus immobilized groups). Error bars indicate the standard error of the mean. 


\section{Discussion}

The scientific literature suggests that sensorimotor deprivation leads to a quick update of the sensorimotor representation of an immobilised hand following 24 hours of immobilisation or of both the immobilised and non-immobilised hands following 48 hours of immobilisation. The present experiment goes further by specifically examining whether left-hand immobilisation for 48 hours would selectively affect the upper-limb representation or would extend to another body part, such as lower-limb (foot) representation. Thus, we compared the participants' performances on two body-part mental rotation tasks (with either hand images or foot images) before and after left-hand immobilisation.

The body-part mental rotation tasks are well known to implicitly trigger a motor imagery strategy and thus reflect the central processing of the sensorimotor system (Parsons, 1994). In the present experiment, the slower responses observed for both control and immobilised participants when judging laterality of images corresponding to the most awkward or biomechanically constraining postures confirmed their use of a motor imagery strategy. We also replicated the commonly reported laterality effect (Ionta et al., 2007; Ionta \& Blanke, 2009; Ni Choisdealbha, Brady, \& Maguinness, 2011; Parsons, 1994; Toussaint \& Meugnot, 2013), with slower responses for the non-dominant than for the dominant hand and foot. These results confirmed that both controls and immobilised participants in the present experiment used a motor imagery strategy when solving the body-part mental rotation tasks, regardless of the nature of the displayed images (i.e., hand versus foot). Therefore, the mental rotation tasks used in this study are appropriate to examine the immobilisation-induced effects on sensorimotor representations. Does 48 hours of left-hand non-use specifically impair the effector-system corresponding to the restricted limb (the upper-limb system) or extend to another effector-system (the lower-limb system)? 
The new finding of the present experiment is to show that short-term upper-limb immobilisation affects the sensorimotor representation of the restricted effector-system (the upper-limb) without disturbing the internal representation of another body part when it depends on another effector-system (the lower-limb). Indeed, with regard to the immobilisation-induced effects on inter-limb transfer, the results of this study showed a different pattern for upper-limb and lower-limb. An important finding shows that two days of left-hand immobilisation slowed the recognition of hand images but did not affect the speed of laterality judgment of foot images. More precisely, the immobilised participants benefited more from the task-repetition effect for foot images than for mental rotation of hand images. The attenuated effect of task repetition when participants had to judge the laterality of hand images following short-term upper-limb immobilisation (either the left or the right hand) is in agreement with previous studies (Meugnot et al., 2014; Meugnot \& Toussaint, 2015) in which the immobilisation-induced effect was studied with regard to motor versus visual imagery strategies. The authors demonstrated that limb non-use specifically affects motor imagery, while visual imagery was independent of peripheral perturbations. Moreover, comparison between various experiments shows that the general upper-limb sensorimotor representation was impaired following 48 hours of left-hand non-use (Meugnot \& Toussaint, 2015; Toussaint \& Meugnot, 2013), while the sensorimotor representation of the restricted hand was only impaired after 24 hours of non-use (Meugnot et al, 2014, 2015). Consequently, the present finding suggest that the negative impact of sensorimotor deprivation could be specific to the sensorimotor representation of a specific body region (i.e., the upper-limb representation in the present experiment). It may be, however, that the slowdown of the sensorimotor processes due to upper-limb immobilisation takes more time to spread to the lower-limbs, challenging the selective impairment of body-part non-use. 
Other studies have tested the selective effect of peripheral changes using hand and foot mental rotation tasks (Fiorio, Tinazzi, \& Aglioti, 2006; Ionta et al., 2007; Ionta \& Blanke, 2009). Ionta and collaborators showed the selective influence of hand posture adopted by participants during the mental rotation of hands. When participants were holding their hands behind their back, response times for hand identification increased compared to a "standard" condition, i.e., when the task was performed with hands on the legs. This postural effect was absent for foot images, indicating the specific effect of body-part posture on motor imagery processes. In another experiment examining peripheral sensorimotor impairments (i.e., focal hand dystonia), Fiorio et al. (2006) reported a selective slowing of laterality judgment of hand images but not foot images. Overall, these findings are consistent with the idea that peripheral perturbations selectively affect the limb representation or the effector-system corresponding to the body part that undergoes sensorimotor deprivation. Consequently, although the laterality judgment of hand and foot images both depend on the use of sensorimotor processes, these processes are based on a specific effector-system representation rather than an overall body representation. It is possible that the present result is task dependent, and some questions remain about the induced effect of sensorimotor deprivation on accurate movement parameterisation or movement output.

Because several cognitive processes are implied in a body-part recognition task, we can ask which of these processes are affected by short-term limb non-use. Parsons and collaborators (Parson, 1987; Parson, Fox, Downs, Glass, Hirsch, Martin, Jerabek, \& Lancaster, 1995) argued that hand recognition relies on a two-stage identification process. A rapid and implicit initial analysis of hand shape (perceptive identification stage) followed by the mental rotation of participant's own hand (mental rotation stage) allows the participant to confirm the previous implicit judgment of handedness. Therefore, in a mental rotation task, the response time reflects the sum of these processes. It is commonly accepted in the literature 
that the effect of the angle of rotation on response times highlights the mental rotation processes, i.e., the movement simulation processes when a body image is displayed on the computer screen, with participants imagining actions that would allow them to move from their current position to that of the image. In our experiment, the consequence of 48 hours of left-hand immobilisation did not modify the response time profile as a function of images rotation (i.e., the mental rotation stage). Therefore, the slowdown of responses observed in the hand laterality task following 2 days of left-hand immobilisation may due to less efficient and slower processes implied specifically in the implicit perceptive identification stage. This initial identification analysis of hand images is based on a stored body schema that is limbindependent, as also suggested by immobilisation-induced neural changes observed in a study based on transcranial magnetic stimulation (Facchini et al., 2002). Four days of immobilisation of the ring and little fingers induced a decrease in cortical excitability of the restricted fingers and also on homotopic regions of the cortex.

In the present experiment, the immobilisation-induced effect that appeared only at the initial stage of the hand mental rotation task may be task-specific. Indeed, in a hand laterality task in which participants gave their response by pressing a response-key with their unrestricted limb, Toussaint and Meugnot (2013) reported changes at both the perceptive identification and motor imagery stages. It may be that the key-pressing responses, which consume sensorimotor resources, do not allow sufficient allocation of sensorimotor resources to efficiently simulate action, leading participants to favor a visual imagery strategy (versus a motor imagery strategy), as reported by the authors. In contrast, when a response is given verbally, as in the present experiment (see also Meugnot et al., 2014), sufficient sensorimotor resources may remain to correctly simulate actions. Further research is needed to examine whether the effects of limb non-use may vary as a function of the complexity of the task with regard to sensorimotor resources that remain available to simulate actions. 


\section{References}

Avanzino, L., Bassolino, M., Pozzo, T., \& Bove, M. (2011). Use-dependent hemispheric balance. Journal of Neuroscience, 31, 3423-3428. doi:10.1523/JNEUROSCI.489310.2011

Avanzino, L., Pelosin, E., Abbruzzese, G., Bassolino, M., Pozzo, T., \& Bove, M. (2013). Shaping motor cortex plasticity through proprioception. Cerebral Cortex, 24, 28072814. doi:10.1093/cercor/bht139

Bassolino, M., Bove, M., Jacono, M., Fadiga, L., \& Pozzo, T. (2012). Functional effect of short-term immobilization: kinematic changes and recovery on reaching-to-grasp. Neuroscience, 215, 127-134. doi:10.1016/j.neuroscience.2012.04.019

Curtze, C., Otten, B., \& Postema, K. (2010). Effects of lower limb amputation on the mental rotation of feet. Experimental Brain Research, 201, 527-534. doi:10.1007/s00221-009$2067-z$

de Lange, F. P., Hagoort, P., \& Toni, I. (2005). Neural topography and content of movement representations. Journal of Cognitive Neuroscience, 17, 97-112. doi:10.1162/0898929052880039

Facchini, S., Romani, M., Tinazzi, M., \& Aglioti, S. M. (2002). Time-related changes of excitability of the human motor system contingent upon immobilization of the ring and little fingers. Clinical Neurophysiology, 113, 367-75.

Fiorio, M., Tinazzi, M., \& Aglioti, S. M. (2006). Selective impairment of hand mental rotation in patients with focal hand dystonia. Brain, 129, 47-54. doi:10.1093/brain/awh630

Huber, R., Ghilardi, M. F., Massimini, M., Ferrarelli, F., Riedner, B. A., Peterson, M. J., \& Tononi, G. (2006). Arm immobilization causes cortical plastic changes and locally decreases sleep slow wave activity. Nature Neuroscience, 9, 1169-1176. doi:10.1038/nn1758 
Ionta, S., \& Blanke, O. (2009). Differential influence of hands posture on mental rotation of hands and feet in left and right handers. Experimental Brain Research, 195, 207-217. doi:10.1007/s00221-009-1770-0

Ionta, S., Fourkas, A. D., Fiorio, M., \& Aglioti, S. M. (2007). The influence of hands posture on mental rotation of hands and feet. Experimental Brain Research, 183, 1-7. doi:10.1007/s00221-007-1020-2

James, W. (1980). The Principles of Psychology. New York: Holt.

Jeannerod, M. (2001). Neural simulation of action: a unifying mechanism for motor cognition. Neuroimage, 14, 429-439. doi:10.1006/nimg.2001.0832

Johnson, S.H., Sprehn, G., \& Saykin (2002). Intact motor imagery in chronic upper limb hemiplegics: Evidence for activity-independent action representations. Journal of Cognitive Neuroscience, 14, 841-852. doi:10.1162/089892902760191072

Kosslyn, S. M., DiGirolamo, G. J., Thompson, W. L., \& Alpert, N. M. (1998). Mental rotation of objects versus hands: Neural mechanisms revealed by positron emission tomography. Psychophysiology, 35, 151-161.

Meugnot, A., Agbangla, N. F., Almecija, Y., \& Toussaint, L. (2015). Motor imagery practice may compensate for the slowdown of sensorimotor processes induced by short-term upper-limb immobilization. Psychological Research, 79, 489-499. doi:10.1007/s00426-014-0577-1

Meugnot, A., Almecija, Y., \& Toussaint, L. (2014). The embodied nature of motor imagery processes highlighted by short-term limb immobilization. Experimental Psychology, 61, 180-186. doi:10.1027/1618-3169/a000237

Meugnot, A., \& Toussaint, L. (2015). Functional plasticity of sensorimotor representations following dominant versus non-dominant hand short-term immobilization. Acta Psychologica, 155, 51-56. doi: 10.1016/j.actpsy.2014.11.013 
Moisello, C., Bove, M., Huber, R., Abbruzzese, G., Battaglia, F., Tononi, G., \& Ghilardi, M. F. (2008). Short-term limb immobilization affects motor performance. Journal of Motor Behavior, 40, 165-176. doi:10.3200/JMBR.40.2.165-176

Ni Choisdealbha, A., Brady, N., \& Maguinness, C. (2011). Differing roles for the dominant and non-dominant hands in the hand laterality task. Experimental Brain Research, 211, 73-85. doi:10.1007/s00221-011-2652-9

Nico, D., Daprati, E., Rigal, F., Parsons, L.M., \& Sirigu, A. (2004). Left and right hand recognition in upper limb amputees. Brain, 127, 120-132. doi:10.1093/brain/awh006

Oldfield, R. C. (1971). The assessment and analysis of handedness: the Edinburgh inventory. Neuropsychologia 9, 97-113.

Parsons, L. M. (1987). Imagined spatial transformations of one's body. Journal of Experimental Psychology: General, 116, 172-191.

Parsons, L. M. (1994). Temporal and kinematic properties of motor behavioral reflected in mentally simulated action. Journal of Experimental Psychology: Human, Perception and Performance, 20, 709-730.

Parsons, L. M., Fox, P. T., Downs, J. H., Glass, T., Hirsch, T. B., Martin, C. C. , Jerabek, P. A., \& Lancaster, J. L. (1995). Use of implicit motor imagery for visual shape discrimination as revealed by PET. Nature, 37, 54-58.

Pascual-Leone, A., Amedi, A., Fregni, F., \& Merabet, L. B. (2005). The plastic human brain cortex. Annual Review of Neuroscience, 28, 377-401. doi:10.1146/annurev.neuro.27.070203.144216

Shepard, R. N., \& Metzler, J. (1971). Mental rotation ofthree-dimensional objects. Science, $171,701-703$. 
Toussaint, L., \& Meugnot, A. (2013). Short-term limb immobilization affects cognitive motor processes. Journal of Experimental Psychology: Learning, Memory and Cognition, 39, 623-632.doi:10.1037/a0028942 